\title{
Appetitive Instrumental Learning Requires Coincident Activation of NMDA and Dopamine D1 Receptors within the Medial Prefrontal Cortex
}

\author{
Anne E. Baldwin, ${ }^{1}$ Kenneth Sadeghian, ${ }^{2}$ and Ann E. Kelley ${ }^{1,2}$ \\ ${ }^{1}$ Neuroscience Training Program and ${ }^{2}$ Department of Psychiatry, University of Wisconsin-Madison Medical School, \\ Madison Wisconsin 53719-1176
}

Through its complex role in cognition, memory, and emotion, the mammalian prefrontal cortex is thought to contribute to the organization of adaptive behavioral actions. In the present studies we examined the role of dopaminergic D1 and glutamatergic NMDA receptors within the prefrontal cortex of the rat during the development of adaptive instrumental learning. Hungry rats with bilateral indwelling cannulas aimed at the medial prefrontal cortex were trained to lever-press for food. Infusion of the selective D1 antagonist SCH-23390 (0.15, 0.3, $3.0 \mathrm{nmol})$ dosedependently impaired acquisition of this behavior. Higher doses also impaired expression of this task. Co-infusion of the lowest dose of SCH 23390 with a low dose of the NMDA antagonist AP-5 (0.5 nmol), each of which had no effect on learning when infused alone, potently reduced the ability to acquire the response. Inhibition of intracellular protein kinase $A$ with the selective PKA inhibitor Rp-cAMPS also disrupted acquisition, suggesting that PKA is an intracellular substrate for a D1NMDA receptor interaction. In control experiments, drug infusions that impaired learning did not affect food intake or locomotion, suggesting a specific effect on learning. We hypothesize that coincident detection of D1-NMDA receptor activation and its transcriptional consequences, within multiple sites of a distributed corticostriatal network, may represent a conserved molecular mechanism for instrumental learning.

Key words: NMDA; dopamine; D1; operant responding; protein kinase $A$; reward; reinforcement
The medial prefrontal cortex (mPFC) is implicated in many cognitive functions, including working memory, temporal organization of behavior, and adaptation of behavioral strategies (Goldman-Rakic, 1995a; Rolls, 2000). There is evidence that the mPFC and other regions such as the amygdala and nucleus accumbens are part of a distributed corticostriatal network mediating certain aspects of learning and the expression of various motivated behaviors (Gaffan and Murray, 1990; McDonald and White, 1993; Goldman-Rakic, 1995b; Houk and Wise, 1995; Floresco et al., 1997; Kelley, 1999). The components of this network are interconnected via glutamatergic fibers (Christie et al., 1985; Kita and Kitai, 1990; Brog et al., 1993) and receive dopaminergic afferents from the ventral tegmental area (Lindvall et al., 1978; Beckstead et al., 1979).

Dopamine transmission in the mPFC and nucleus accumbens is likely to be crucial for acquisition of instrumental behaviors (Sawaguchi and Goldman-Rakic, 1991; Salamone, 1994; Beninger and Miller, 1998). Presentation of primary rewards increases dopamine in both these regions during initial operant learning, although later in learning conditioned stimuli may evoke similar increases (Richardson and Gratton, 1996; Izaki et al., 1998). These results suggest that dopamine may mediate the formation of an association between relevant stimuli and reward, whereas after learning, dopaminergic activity is associated with salient

Received July 3, 2001; revised Nov. 1, 2001; accepted Nov. 8, 2001.

This work was supported by National Institute of Drug Abuse Grant DA04788 (A.E.K.). We acknowledge the kind assistance of Dr. Amy Harms of the University of Wisconsin-Madison Biotechnology Center.

Correspondence should be addressed to Ann E. Kelley, Department of Psychiatry, University of Wisconsin-Madison, 6001 Research Park Boulevard, Madison, WI 53719-1176. E-mail: aekelley@facstaff.wisc.edu.

Copyright (ㄷ) 2002 Society for Neuroscience $0270-6474 / 02 / 221063-09 \$ 15.00 / 0$ environmental cues rather than primary rewards (Robinson and Berridge, 1993; Schultz et al., 1993; Berridge and Robinson, 1998; Horvitz, 2000).

Glutamate NMDA receptor activation in the $\mathrm{mPFC}$ and nucleus accumbens has also been implicated in various associative processes (Verma and Moghaddam, 1996; Kelley et al., 1997). Previous research has shown that antagonism of NMDA receptors within the mPFC, basolateral amygdala, or nucleus accumbens impairs acquisition, but not expression, of appetitive instrumental learning (Kelley et al., 1997; Smith-Roe et al., 1999; Baldwin et al., 2000). Additionally, recent work has demonstrated that co-infusion of low, and individually ineffective, doses of NMDA and dopamine D1 receptor antagonists into the nucleus accumbens also significantly impairs task acquisition, suggesting that a synergistic interaction between these receptor types may be a neural substrate of the learning process (Smith-Roe and Kelley, 2000). There is electrophysiological and molecular evidence for NMDA-D1 interactions and resultant convergence of these two systems via the cAMP-cAMP-dependent protein kinase (PKA) cascade (Cepeda et al., 1993; Konradi et al., 1996; Wickens et al., 1996; Das et al., 1997; Cepeda and Levine, 1998; Kerr and Wickens, 2001). Given that the mPFC, like the nucleus accumbens, receives a convergence of dopaminergic and glutamatergic inputs, we hypothesized that a similar interaction in the $\mathrm{mPFC}$ may underlie neuronal adaptation during appetitive instrumental learning.

The present experiments examined the effects of intra-mPFC infusions of three different doses of the selective D1 receptor antagonist SCH-23390, a low dose of the competitive NMDA receptor antagonist AP-5, combined low doses of AP-5 and SCH-23390, and the selective PKA inhibitor Rp-cAMPS on appetitive instrumental learning. We report here that, as previously 
found for the nucleus accumbens, coactivation of D1 and NMDA receptors within the $\mathrm{mPFC}$ is necessary for appetitive instrumental learning and that these effects may involve intracellular activation of PKA.

\section{MATERIALS AND METHODS}

\section{Animals and surgery}

A total of 85 male Sprague Dawley rats (Harlan, Madison, WI) were used in these experiments. Rats were housed in groups of two, maintained on a $12 \mathrm{hr}$ light/dark cycle, and handled daily to minimize stress. Rats weighed $\sim 300 \mathrm{gm}$ at the beginning of the experiment and were maintained with food and water ad libitum before surgery. After several days of recovery from surgery, food was restricted to bring the rats to $\sim 85 \%$ of their free-feeding, presurgical weight. To accomplish this, each rat was given a premeasured amount (8-14 gm, depending on weight and calculated weight loss) of regular chow (Rodent Diet [W]8604; Harlan Teklad, Madison, WI) at the same time each day. During training, animals were fed at the conclusion of each day's test session. Care of the rats was in accordance with the University of Wisconsin-Madison Institutional Animal Care and Use Committee guidelines.

After anesthesia with ketamine-xylazine $(87 / 13 \mathrm{mg} / \mathrm{kg})$, all rats were implanted with bilateral chronic indwelling stainless steel cannulas (23 gauge, $0.64 \mathrm{~mm}$ ) according to standard flat-skull stereotaxic procedures. Cannulas were cemented to the skull using dental acrylic anchored with stainless steel screws. Stainless steel wire stylets prevented occlusion of the cannulas. For all experiments, cannulas were aimed at the medial prefrontal cortex using the following coordinates (in $\mathrm{mm}$ from bregma): anteroposterior +2.8 , mediolateral \pm 0.5 , dorsoventral -3.3 .

\section{Drugs and microinfusions}

$R(+)$-7-chloro-8-hydroxy-3-methyl-1-phenyl-2,3,4,5-tetrahydro-1H-3-benzazepine hydrochloride (SCH-23390), (+/-)-2-amino-5-phosphonopentanoic acid (AP-5), and Rp-adenosine 3',5'-cyclic monophosphothioate triethlyamine (Rp-cAMPS) were obtained from Research Biochemicals International (Natick, MA). Drugs were dissolved in isotonic sterile saline. For experiments 1-5, intracerebral microinfusions of drug or vehicle were always bilateral in a volume of $0.5 \mu \mathrm{l} / \mathrm{side}$. For experiment 6 , the volume was $1.0 \mu \mathrm{l} /$ side. For experiment 1 , the doses of SCH-23390 were $3 \mathrm{nmol}(1 \mu \mathrm{g}), 0.3 \mathrm{nmol}(0.1 \mu \mathrm{g})$, and $0.15(0.05 \mu \mathrm{g}) \mathrm{nmol}$ per infusion site. For experiment 2 , the dose of AP-5 was $0.5 \mathrm{nmol}(0.1 \mu \mathrm{g})$ per infusion site. The doses of SCH-23390 and AP-5 were chosen on the basis of previous research that found that infusion of $3 \mathrm{nmol}$ of SCH23390 into the nucleus accumbens core significantly impaired both acquisition and expression of appetitive instrumental learning, whereas infusion of either $0.5 \mathrm{nmol}$ of AP- 5 or $0.3 \mathrm{nmol}$ of SCH-23390 into the same region had no effects (Smith-Roe and Kelley, 2000). For experiment 3 , a combination inf usion of the low doses of AP-5 (0.5 nmol) and SCH-23390 (0.15 nmol) was administered. For experiment 4, Rp-cAMPS was administered at a dose of $20 \mathrm{nmol}(8.9 \mu \mathrm{g})$ per infusion site. The dose of Rp-cAMPS was chosen based on previous results showing that infusions of Rp-cAMPS into the nucleus accumbens significantly impaired appetitive instrumental learning in a dose-dependent manner (Baldwin et al., 2002). Experiments 5 and 6 examined the effects of microinfusion of either the high dose of SCH-23390 $(3 \mathrm{nmol})$, the combination low doses of AP-5 $(0.5 \mathrm{nmol})$ and SCH-23390 $(0.15 \mathrm{nmol})$, or Rp-cAMPS $(20 \mathrm{nmol})$ on measures of spontaneous locomotor and feeding behavior. Microinfusions were performed with a microdrive pump (Harvard Apparatus, South Natick, MA). For all experiments, after removal of the stylets, drug or vehicle was infused by lowering 30 gauge $(0.3 \mathrm{~mm})$ injector cannulas to the site of infusion $(-4.8 \mathrm{~mm}$ from the skull surface). For experiments $1-5$, infusion delivery time was $1 \mathrm{~min}$ $33 \mathrm{sec}$ (the microdrive pump was set at $0.32 \mu \mathrm{l} / \mathrm{min}$ ) followed by $1 \mathrm{~min}$ of diffusion time. Experiment 6, infusion delivery time was 2 min (the microdrive pump was set at $0.5 \mu \mathrm{l} / \mathrm{min}$ ) followed by $1 \mathrm{~min}$ of diff usion time. The injectors were then removed, and the stylets were replaced. The rats were tested within 5 min of infusion.

\section{Mass spectrometry}

To ensure that SCH-23390 and AP-5 were not reacting in solution, 10 or $20 \mu \mathrm{M}$ samples of SCH-23390, AP-5, and a SCH-23390-AP-5 mixture were analyzed by electrospray ionization mass spectrometry (Applied Biosystems/MDS SCIEX API365, Foster City, CA) by the University of Wisconsin-Madison Biotechnology Center. Drugs were dissolved in dis- tilled water, and samples were run in both positive and negative ion mode. Expected peaks were found for both the SCH-23390 and AP-5 solutions. When the SCH-23390-AP-5 mixture was analyzed in positive ion mode, only a peak for SCH-23390 was evident. Negative ion mode gave low signals for both SCH-23390 and AP-5 and nothing else except for known impurities. Thus, no new compound was detected.

\section{Testing apparatus}

Operant chambers (Coulbourn Instruments, Allentown, PA) equipped with two retractable levers, a house light, a red signal light, a food pellet delivery system, and a food trough with photosensors were used for experiments 1-4. Stimulus events and data acquisition were controlled by computer using Graphic State Notation (Coulbourn Instruments, Allentown, PA). For experiments 5 and 6 , the testing environment consisted of a clear polycarbonate cage with a wire mesh floor and top.

\section{Behavioral testing and experimental design}

Experiments 1-4. Animals were tested for 11 or $16 \mathrm{~d}$, depending on the experiment, for acquisition of a lever-press response for food. All animals were habituated to the operant chambers and infusion procedure once a day for the $3 \mathrm{~d}$ before the beginning of each experiment. During the first $2 \mathrm{~d}$ of habituation, each animal received a mock infusion in which injectors of the same length as the guide cannulas were lowered and the microdrive pump was turned on, but no infusion was delivered. Animals were then placed in the operant chambers for $15 \mathrm{~min}$ with the house light on, levers were retracted, and sugar pellets available in the food trough. On the third (last) habituation day, all animals received a saline microinf usion $(0.5 \mu \mathrm{l}$ for experiments $1-3$ and $1 \mu \mathrm{l}$ for experiment 4) to the final site of drug delivery and were again placed in the operant chambers as on the first $2 \mathrm{~d}$ of habituation.

On the first and second days of testing, crushed sugar pellets were placed on the correct (rewarded) lever, which was randomly assigned to each animal. Responding on the correct lever resulted in the following sequence of stimuli: house light offset at the same time as a red signal light onset, followed $1 \mathrm{sec}$ later by delivery of a sugar pellet (Dustless Precison Pellets, sucrose, $45 \mathrm{mg}$, Bio-Serv, Frenchtown, NJ) to the food trough. Throughout testing, the first 20 correct lever presses in each session were rewarded on a fixed ratio 1 schedule such that each correct press resulted in delivery of a single pellet. Correct presses after the first 20 were rewarded on a variable-ratio 2 schedule, such that, on average, an animal was rewarded for every other lever press. Responding on the incorrect lever had no consequences. Correct and incorrect lever presses as well as nosepokes into the food trough (photobeam breaks) were recorded.

On days 1-5 of testing, each rat received the appropriate microinfusion immediately before it was placed in an operant chamber. For experiment 1 , rats received either a low $(n=8)$, medium $(n=9)$, or high $(n=9)$ dose of SCH-23390 or saline $(n=8)$. For experiment 2, rats received either AP-5 $(n=8)$ or saline $(n=8)$. For experiment 3, rats receive either the combined low doses of SCH-23390 and AP-5 $(n=10)$ or saline $(n=7)$. For experiment 4 , rats received Rp-cAMPS $(n=8)$. After the infusion days, all rats in all experiments were tested without inf usion for days $6-10$. For experiment 1 , animals receiving the low $(0.15$ $\mathrm{nmol}$ ) dose of SCH-23390 or vehicle received a final infusion on day 11 , whereas the animals receiving the high $(3 \mathrm{nmol})$ and medium $(0.3 \mathrm{nmol})$ doses of SCH-23390 were tested without inf usion until day 16 when they were given a final drug infusion. On day 11, all animals in experiment 2 also received the same infusion as on the first days of testing. All animals in experiment 3 received drug or vehicle infusions on day 11, were tested for an additional $4 \mathrm{~d}$ without infusion, and then received a final infusion on day 16. Animals in experiment 4 received a drug or vehicle infusion on day 11 and were then tested for an additional $5 \mathrm{~d}$ without infusion. The specific rationale for these later injections is provided in Results.

It should be noted that the testing apparatus, including the size of the levers, food pellet delivery system, and computer program, was updated between previously published work (Kelley et al., 1997; Baldwin et al., 2000) and the present studies. This change has resulted in a somewhat different acquisition curve for control animals. We find that, with the new system, animals learn at a slightly lower rate than for our previously published results.

Experiments 5 and 6 . To ascertain the ability of the drugs used to produce nonspecific effects on locomotor or motivated behavior, experiments 5 and 6 examined the effects of drug infusion on several measures 

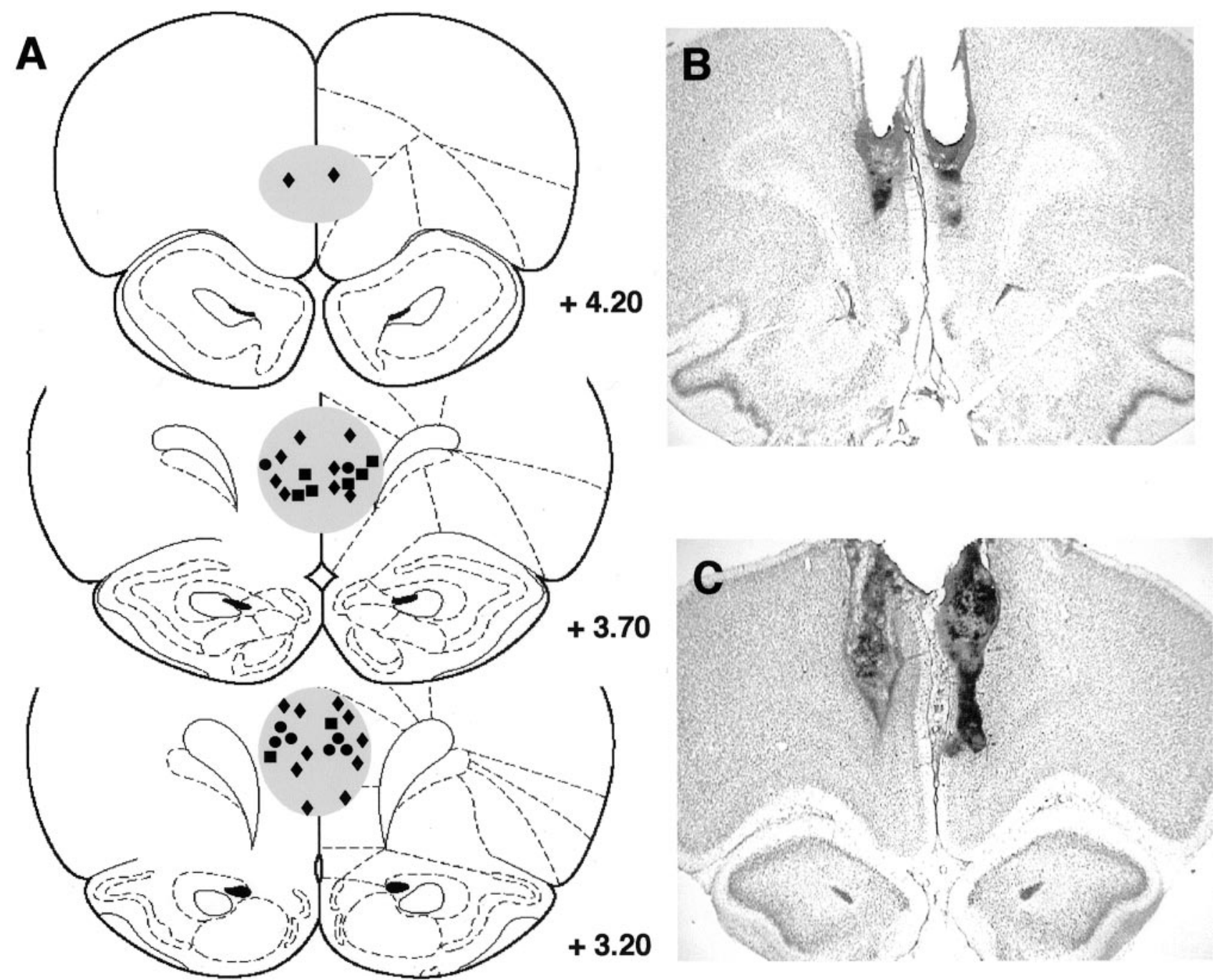

Figure 1. Histological reconstructions of cannula placements in the various experiments and representative histology. A, Histological sections were examined under a light microscope, and the site of infusion was estimated. Each pair of symbols on a particular section represents one rat. For this reconstruction, representative infusion sites were plotted for four rats receiving the high dose (3 nmol) of SCH-23390 in experiment 2 ( $(0)$ and four control rats from experiment $3(\square)$. Infusion sites for all animals receiving the combined low doses of AP-5 (0.5 nmol) and SCH-23390 (0.15 nmol) in experiment $3(\checkmark)$ are also plotted. The shaded regions represent the areas containing all inf usion sites from all experiments. From Paxinos and Watson (1998). Adapted with permission. Representative histology from a rat treated with the high dose of SCH-23390 (B) and the combined low doses of AP-5 and SCH-23390 (C).

of locomotor and feeding behavior. For experiment 5, animals $(n=10)$ were habituated to the infusion procedure and testing environment for $3 \mathrm{~d}$ before testing. On these days each animal received a mock or saline inf usion (as described above) and was then placed in the test chamber for $\sim 1 \mathrm{hr}$ with regular rat chow scattered on the floor and water available $a d$ libitum. On the three test days, animals received a microinf usion of either the high dose of SCH-23390 (3 nmol), the combination low doses of SCH-23390 $(0.15 \mathrm{nmol})$ and AP-5 $(0.5 \mathrm{nmol})$, or vehicle immediately before testing. Drugs were administered in a counterbalanced design over the three test days. During testing an observer blind to the treatment condition used an event recorder connected to a computer to measure duration of feeding, locomotor activity (frequency of crossing the center of the cage), rearing activity, and total duration of feeding. Total food intake in grams was also measured. Testing sessions were 30 min in length. For experiment 6 , animals $(n=8)$ received an inf usion of Rp-cAMPS (20 nmol) or vehicle in a counterbalanced design over two days. Testing procedures were otherwise identical to those for experiment 5 .

\section{Histological analysis}

At the conclusion of the experiments, all rats were deeply anesthetized with sodium pentobarbital and perfused transcardially with isotonic saline followed by $10 \%$ formalin. The brains were stored in a $20 \%$ sucrose-formalin mixture before sectioning. Sixty-micrometer sections were stained with cresyl violet and examined for location of inf usion sites using light microscopy. A reconstruction of the inf usion sites and representative histological sections are shown in Figure 1.

\section{Statistical analysis}

Data were analyzed by multifactorial ANOVA. The lever press data (total correct and incorrect lever presses) was analyzed with treatment as the between-subjects factor and days and lever (correct or incorrect) as the within-subjects factors. Days and nosepokes into the food trough were the within-subjects factors for the nosepoke data analysis. Generally, lever-press and nosepoke data were analyzed in three sets: infusion days, postinfusion days, and a comparison of the last noninfusion day to the reinfusion (final) day, to test for effects of the drug treatment once behavior was learned. Analyses of simple main effects or post hoc analyses were conducted where appropriate. Note that data for the RpcAMPS group in experiment 4 was compared with that for control animals in experiment 3 . Data for experiments 5 and 6 were analyzed by ANOVA with treatment as the within-subjects factor. 


\section{A. Lever presses}

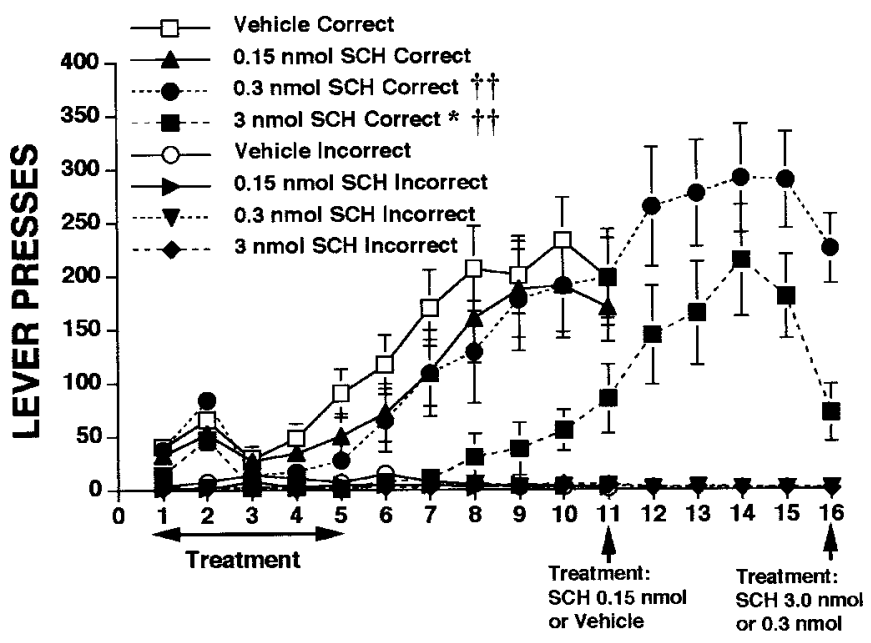

B. Nosepokes into food tray

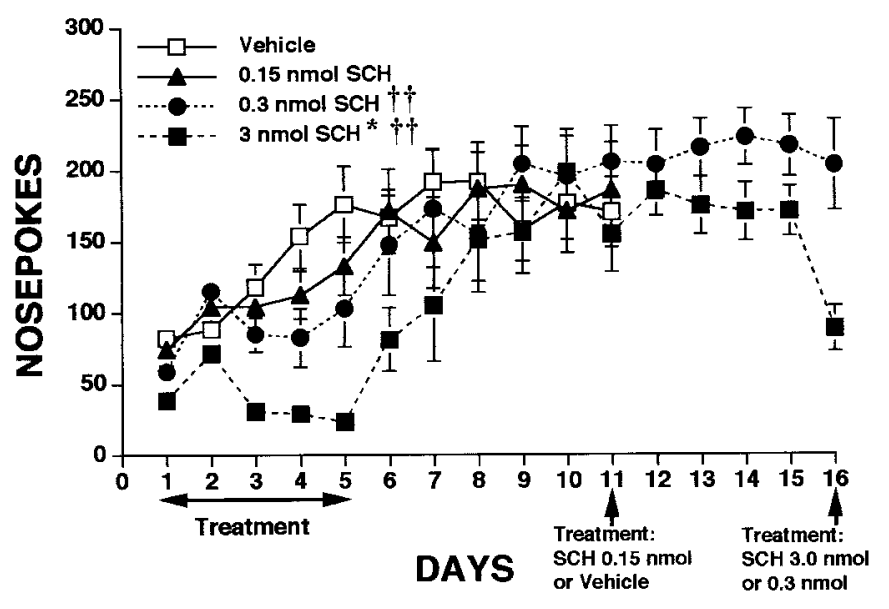

Figure 2. Influence of intra-mPFC infusions of high, medium, or low doses of the D1 receptor antagonist SCH-23390 on appetitive instrumental learning. Animals received infusions of SCH-23390 or saline on the first 5 test days and were tested without infusions on days $6-10$. On day 11 , animals receiving the low dose of SCH-23390 or vehicle were given a final infusion, as on days 1-5. Animals receiving the high and medium doses of SCH-23390 were tested for an additional $5 \mathrm{~d}$ without infusion and then received a final drug infusion on day 16 . $A$, Lever presses for food. ${ }^{*} p<$ 0.05 treatment effect; $\dagger \dagger p<0.01$ interactions. $B$, Nosepokes into food tray during learning. ${ }^{*} p<0.05$ treatment effect; $\dagger \dagger p<0.01$ interactions. See Results for details of statistical analysis.

\section{RESULTS}

Experiment 1: infusion of the D1 antagonist SCH-23390 into mPFC dose-dependently impairs instrumental learning

Data depicting the effects of medial prefrontal cortex microinfusions of three different doses of the D1 receptor antagonist SCH-23390 on lever-pressing behavior are presented in Figure $2 A$. Control animals developed a preference for the rewarded lever by day 5 . In contrast, $\mathrm{SCH}-23390$ impaired learning. Analysis of the lever-press data for the infusion days (1-5) revealed a significant effect of treatment $\left(F_{(3,38)}=4.027 ; p=0.0140\right)$, because of a lower level of responding in the group receiving the high dose of SCH-23390 (Student-Newman-Keuls, $p<0.05$ ). Significant day $\times$ treatment $\left(F_{(12,152)}=3.074 ; p=0.0007\right)$ and day $\times$ lever $\times$ treatment $\left(F_{(12,152)}=2.673 ; p=0.0028\right)$ interac- tions as well as a trend toward a lever $\times$ treatment interaction $\left(F_{(3,38)}=2.429 ; p=0.0803\right)$ were also found on days $1-5$. Analysis of partial interactions showed that both the high and medium dose SCH-23390 groups contributed to the significant interactions $(F$ values $>4.80 ; p$ values $<0.01)$. The treatment effect persisted through the postinfusion days $\left(6-10 ; F_{(3,38)}=\right.$ $3.940 ; p=0.0153$ ) with the high dose $\mathrm{SCH}-23390$ group differing from controls (Student-Newman-Keuls; $p<0.05$ ). A significant lever $\times$ treatment interaction was found during the postinfusion days $\left(F_{(3,38)}=3.707 ; p=0.0196\right)$, to which only the high dose SCH-23390 group contributed $\left(F_{(1,38)}=10.974 ; p<0.01\right)$, suggesting that these animals were not discriminating between the correct and incorrect levers as well as the other groups.

To determine if SCH-23390 had any impact on expression of the learned task, animals were reinf used with their original treatment once asymptotic levels were reached. Analysis of the data for days 10-11 for the vehicle and low-dose groups revealed no significant effects for the low dose of SCH-23390. Reinfusion of the high dose of SCH-23390 had a clear decremental effect on responding (Fig. 2A). Analysis of the data for days 15-16 for the high- and medium-dose SCH-23390 groups revealed a significant treatment effect $\left(F_{(1,16)}=8.230 ; p=0.0111\right)$ and lever $\times$ treatment interaction $\left(F_{(1,16)}=8.211 ; p=0.0112\right)$.

Data depicting the effects of SCH-23390 on nosepokes, the initially unconditioned response emitted in the attempt to obtain food, are shown in Figure $2 \mathrm{~B}$. Generally, the pattern of nosepokes was similar to that for lever pressing. During the infusion days (1-5), rats receiving the high dose SCH-22390 exhibited markedly low levels of nosepokes, whereas the other groups generally increased their levels of nosepoking at a steady rate as learning occurred. This difference was confirmed by a significant treatment effect for these days $\left(F_{(3,38)}=8.830 ; p=0.0001\right)$, reflecting the difference between the high dose SCH-23390 and vehicle groups (Student-Newman-Keuls, $p<0.05$ ), A significant day $\times$ treatment interaction $\left(F_{(12,38)}=8.830 ; p=0.0001\right)$ was also found, to which both the high- and medium-dose groups contributed $(F$ values $>5.60 ; p$ values $<0.01)$. This day $\times$ treatment interaction persisted through the postinfusion days $(6-10)\left(F_{(12,152)}=3.687 ; p=0.0001\right)$ with the high and medium dose $\mathrm{SCH}-23390$ groups contributing to it $(F$ values $>3.40 ; p$ values $<0.01)$. Effects of reinfusion of the original treatment once responding was asymptotic were similar to lever-pressing; only the high dose of SCH-23390 significantly reduced nosepoking $\left(F_{(1,38)}=16.134 ; p<0.01\right)$.

\section{Experiment 2: infusion of a low dose of the NMDA antagonist AP-5 into mPFC does not impair instrumental learning}

As is evident in Figure 3, infusion of a low dose $(0.5 \mathrm{nmol})$ of AP-5 into the mPFC had no effect on acquisition or expression of appetitive instrumental learning. Data for lever presses are depicted in Figure $3 A$. All animals distinguished between the correct and incorrect levers from the beginning of the experiment and by day 5 , both the AP- 5 and control animals demonstrated a preference for the rewarded lever. Analysis of the data for the infusion days (1-5) and postinfusion days (6-10) revealed no significant effects of treatment. Additionally, reinfusion of AP-5 on day 11 had no impact on expression of the learned task. Nosepokes were similarly unaffected by infusion of the low dose of AP-5, as can be seen in Figure $3 B$. Both groups of animals increased their levels of nosepoking at a fairly consistent rate over the first several days, reaching an asymptote on days 7-8. Al- 


\section{A. Lever presses}

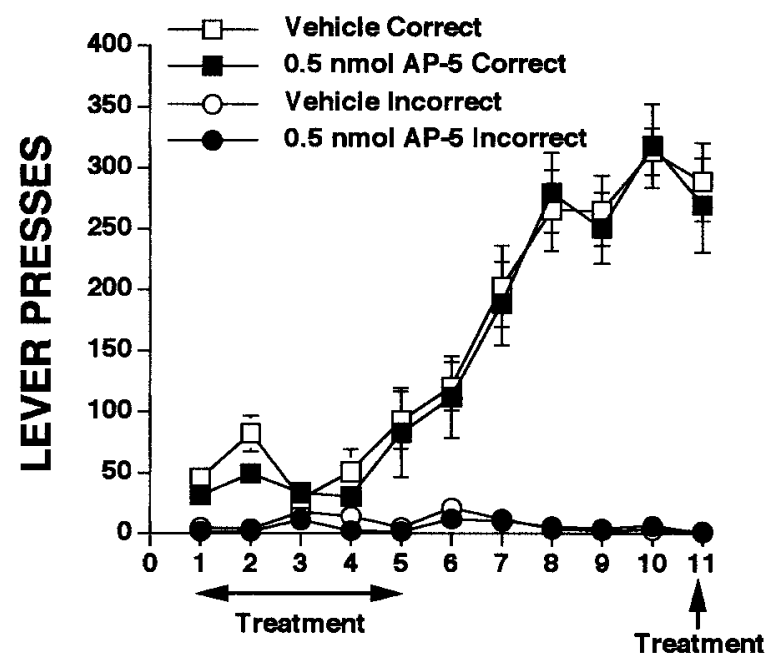

B. Nosepokes into food tray

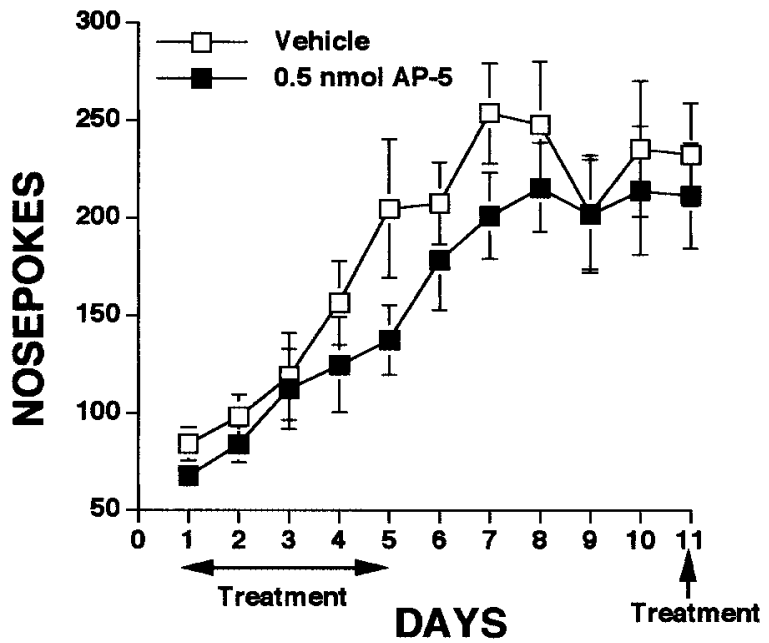

Figure 3. Influence of intra-mPFC infusions of a low dose of the NMDA receptor antagonist AP-5 on appetitive instrumental learning. Animals received infusions of AP-5 or saline on the first 5 test days, no infusions on days $6-10$, and a final infusion of drug or vehicle on day 11. IntramPFC infusions of AP-5 had no impact on either lever presses $(A)$ or nosepokes $(B)$.

though the AP-5 animals tended to have slightly lower levels of nospoking overall, statistical analysis of this data revealed no significant effects for the infusion days or postinfusion days. Similarly, there was no effect of reinfusion of AP-5 on day 11.

Experiment 3: co-infusion of low doses of SCH-23390 and AP-5 into MPFC impairs instrumental learning

Data depicting the effects of infusion of combined low doses of SCH-23390 and AP-5 into the medial prefrontal cortex on leverpressing are presented in Figure $4 A$. Data analysis showed no effect of day or treatment for days 1-5. However, control animals began to show a clear preference for the correct lever on day 5 and thereafter increased their correct lever presses at a steady rate. In contrast, the SCH-23390-AP-5 group never reached control levels of lever-pressing, even after $16 \mathrm{~d}$ of testing. Analysis of postinfusion days $6-10$ revealed a significant treatment effect

\section{A. Lever presses}

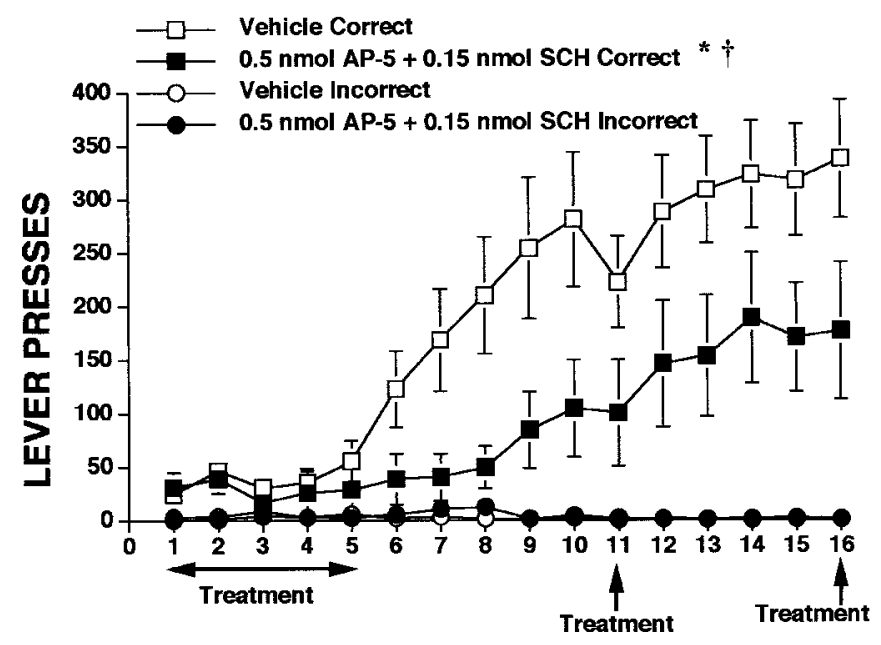

\section{B. Nosepokes into food tray}

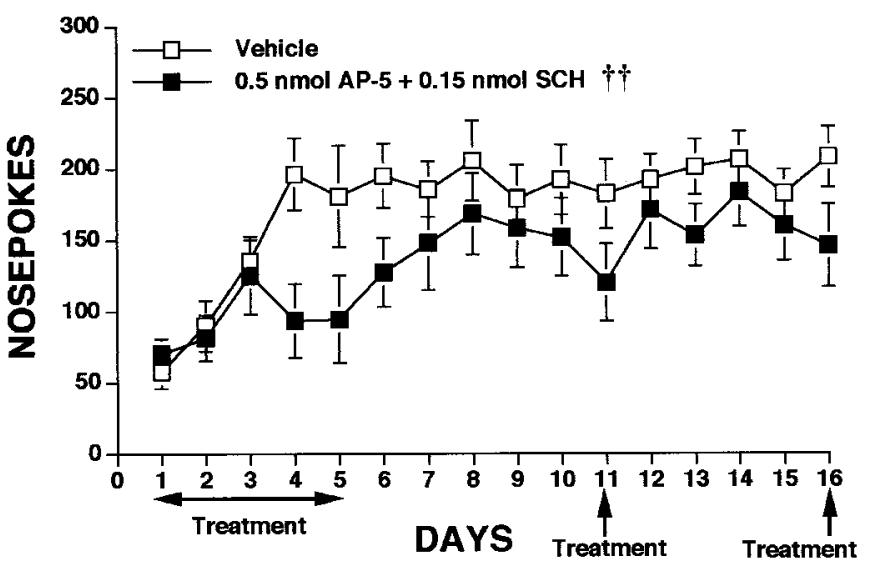

Figure 4. Influence of intra-mPFC co-infusions of low doses of AP-5 and SCH-23390 on appetitive instrumental learning. See legend of Figure 2 for general test procedure. Animals received a subsequent infusion of drug or vehicle on day 11 and again on day 16. $A$, Lever presses for food. ${ }^{*} p<0.05$ treatment effect; $\uparrow p<0.05$ interactions. $B$, Nosepokes into food tray during learning. $\dagger \dagger p<0.01$ interactions. See Results for details of statistics.

$\left(F_{(1,15)}=6.786 ; p=0.0199\right)$ and lever $\times$ treatment interaction $\left(F_{(1,15)}=8.646 ; p=0.0101\right)$. To examine the effects of the combination dose of SCH-23390 and AP-5 on expression of the learned task, both groups were given another microinf usion on day 11. Analysis of days 10-11 showed no effect of treatment. To ensure that the group receiving the combination dose of $\mathrm{SCH}$ 23390 and AP-5 was able to obtain performance levels similar to controls, both groups of animals were run an additional $5 \mathrm{~d}$ (12-16) and were given a final drug or vehicle infusion on day 16. Although the SCH-23390/AP-5 group continued to press at somewhat lower levels than controls, the statistical analyses suggest that this group was able to learn the task as well as control animals and that reinfusion of the combined low doses of SCH-23390 and AP-5 had no effect on expression of the learned task (treatment effect for days $12-15, F_{(1,15)}=3.408, p=0.0847$; day $\times$ treatment interaction for days 15-16 not significant).

The effects of infusion of the combined dose of SCH-23390 and AP-5 on nosepokes are depicted in Figure $4 B$. Control animals quickly increased their nosepoking, reaching a constant level by 


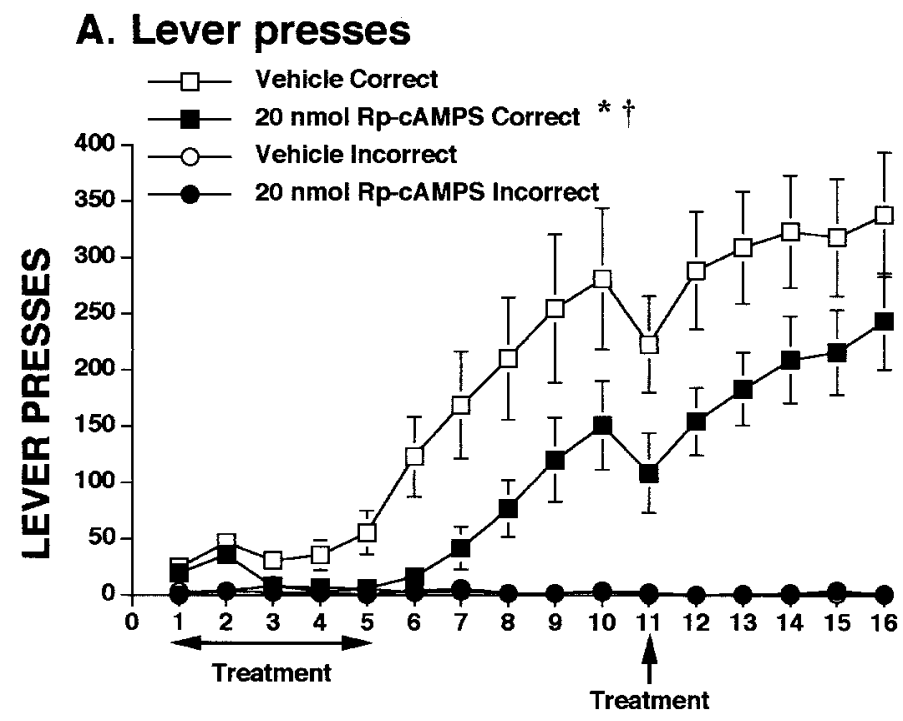

B. Nosepokes into food tray

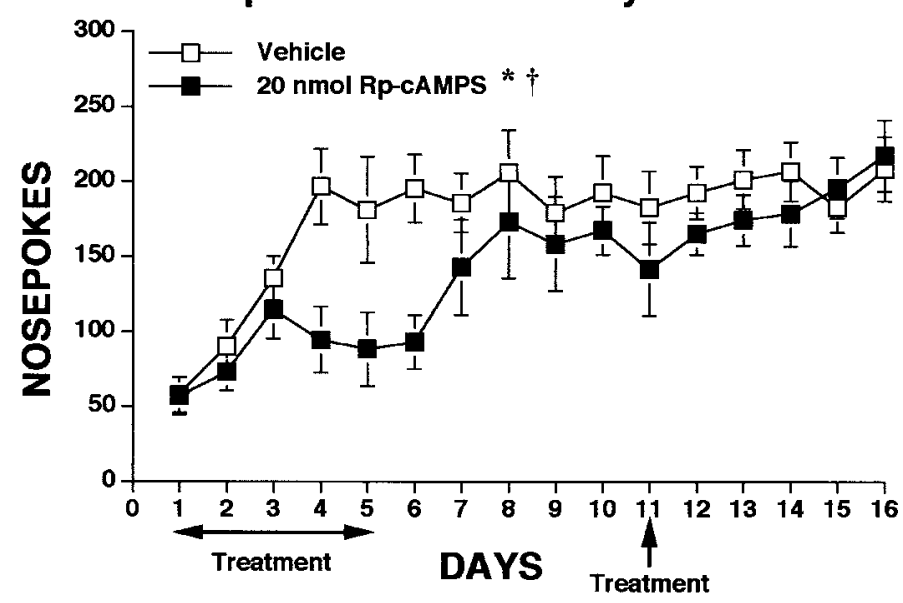

Figure 5. Influence of intra-mPFC co-infusions of PKA inhibitor RpcAMPS on appetitive instrumental learning. See legend of Figure 2 for general test procedure. $A$, Lever presses for food. ${ }^{*} p<0.05$ treatment effect; $\uparrow p<0.05$ interactions. $B$, Nosepokes into food tray during learning. ${ }^{*} p<0.05$ treatment effect; $\dagger p<0.05$ interactions. See Results for details of statistics. Control group is the same as that presented in Figure 4.

day 4. On days 4-5 the SCH-23390-AP-5 group had markedly lower levels of nosepoking than controls. Although the treatment effect for days 1-5 was not significant, the analysis did reveal a significant day $\times$ treatment interaction $\left(F_{(4,60)}=5.509 ; p=\right.$ 0.0014). After cessation of drug treatment, the SCH-23390-AP-5 group quickly reached control levels of nosepoking and, in contrast to the results with lever-pressing, statistical analyses of days $6-10,10-11,12-15$, and 15-16 showed no further significant effects of drug treatment. Thus, although the combined low doses of SCH-23390 and AP-5 had an initial impact on nosepoking, there were no long-term effects of drug administration, and reinfusion did not impair expression of nosepoking behavior.

\section{Experiment 4: inhibition of PKA in mPFC impairs instrumental learning}

Infusion of Rp-cAMPS (20 nmol) into the mPFC significantly impaired both lever-pressing and nosepoke behavior. Data depicting the effects on lever presses are shown in Figure $5 A$. Compared with controls, animals receiving Rp-cAMPS demonstrated very low levels of lever pressing and showed no preference for the correct lever until $2 \mathrm{~d}$ after infusions were ceased. Analysis of the data for the infusion days (1-5) revealed a significant effect of treatment $\left(F_{(1,13)}=7.198 ; p=0.0188\right)$ and day $\times$ treatment $\left(F_{(4,52)}=3.155 ; p=0.0214\right)$ and day $\times$ lever $\times$ treatment $\left(F_{(4,52)}=2.753 ; p=0.0376\right)$ interactions. The difference between control and experimental animals persisted on postinf usion days (days 6-10) $\left(F_{(1,13)}=5.691 ; p=0.0330\right)$. A significant lever $\times$ treatment interaction $\left(F_{(1,13)}=5.708 ; p=\right.$ $0.0327)$ was also evident on days $6-10$, suggesting that the RpcAMPS group was not able to distinguish between the correct and incorrect levers as well as the control group. Reinfusion of Rp-cAMPS did not significantly affect responding.

Rp-cAMPS also inhibited nosepokes, as is depicted in Figure $5 B$. During the infusion days, nosepoke behavior of the $\mathrm{Rp}$ cAMPS group lagged significantly behind that of controls, as confirmed by a significant effect of treatment $\left(F_{(1,13)}=4.737 ; p=\right.$ $0.0485)$ and day $\times$ treatment interaction $\left(F_{(4,52)}=4.415 ; p=\right.$ $0.0038)$. Animals treated with Rp-cAMPS did not begin to express levels of nosepoking that were similar to controls until $2 \mathrm{~d}$ after infusion was ceased. Data analysis revealed no significant effects of Rp-cAMPS on the postinfusion days (6-10), and reinfusion of Rp-cAMPS on day 11 also had no impact on nosepokes.

\section{Experiments 5 and 6: intra-mPFC drug infusions that impair learning do not affect feeding and locomotor behavior}

The results of experiments 5 and 6 , which examined the effects of medial prefrontal cortex inf usion of the high dose of SCH-23390, combined low doses of SCH-23390 and AP-5, or Rp-cAMPS on several measures of feeding and locomotor behavior, are presented in Table 1. No drug treatment altered measures of locomotor or feeding behavior, including total food intake and duration of feeding.

\section{DISCUSSION}

These results show that, in addition to activation of mPFC dopamine D1 receptors, appetitive instrumental learning also requires coincident activation of D1 and glutamate NMDA receptors. Furthermore, activation of PKA may be one possible intracellular mechanism through which the mPFC D1-NMDA receptor interaction is manifest. To our knowledge, the research presented here represents the first direct test of the effects of mPFC dopamine D1 receptor antagonism and coincident D1 and NMDA antagonism on acquisition of appetitive instrumental learning. These results have broad implications for the cellular basis of neuronal adaptation during motor learning and, in light of results of previous research on the nucleus accumbens (Smith-Roe and Kelley, 2000), provide evidence for parallel cellular mechanisms within discrete regions of the proposed neural network mediating such learning. Furthermore, because there is mounting evidence for dopamine-NMDA interactions in behavioral measures associated with chronic drug administration (Karler et al., 1994; Wolf et al., 1994; Kalivas, 1995; Sonsalla, 1995; Wolf and Xue, 1998; Vanderschuren and Kalivas, 2000), these results may be important for current theories of drug addiction, a physiological process that may involve the same neural substrates as appetitive instrumental learning (Robinson and Berridge, 1993; Robinson and Berridge, 2001).

The requirement for activation of $\mathrm{mPFC}$ dopamine $\mathrm{D} 1$ receptors for appetitive instrumental learning is supported by the current finding that a high $(3 \mathrm{nmol})$ and medium $(0.3 \mathrm{nmol})$ dose of SCH-23390 significantly impaired both acquisition and expres- 
Table 1. Influence of intramedial prefrontal cortex drug infusion on feeding and locomotor activity in food-deprived rats (30 min test)

\begin{tabular}{|c|c|c|c|c|c|}
\hline \multirow[b]{3}{*}{ Behavioral measure } & \multicolumn{5}{|l|}{ Treatment } \\
\hline & \multicolumn{3}{|l|}{ Experiment 5} & \multicolumn{2}{|l|}{ Experiment 6} \\
\hline & Vehicle & SCH-23390 & $\mathrm{SCH} / \mathrm{AP}-5$ & Vehicle & Rp-cAMPS \\
\hline Locomotion & $35.0 \pm 5.0$ & $25.5 \pm 3.1$ & $28.7 \pm 3.6$ & $29.3 \pm 3.7$ & $32.1 \pm 3.6$ \\
\hline Rears & $33.2 \pm 5.3$ & $22.0 \pm 3.3$ & $30.5 \pm 4.7$ & $18.1 \pm 4.3$ & $17.8 \pm 1.6$ \\
\hline Feeding duration (sec) & $1061.1 \pm 66.3$ & $1188.1 \pm 28.8$ & $1160.8 \pm 41.2$ & $1276.9 \pm 41.6$ & $1259.1 \pm 19.5$ \\
\hline Total food intake (gm) & $7.6 \pm 0.4$ & $7.1 \pm 0.6$ & $7.8 \pm 0.5$ & $8.1 \pm 0.4$ & $7.8 \pm 0.4$ \\
\hline
\end{tabular}

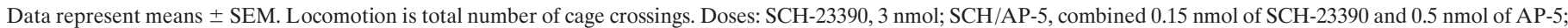
Rp-cAMPS, 20 nmol.

sion of lever pressing and also of nosepoking, the initially unconditioned response emitted in the attempt to obtain food. Although previous research has primarily examined the effects of systemic dopamine manipulations on performance of learned tasks, there is substantial evidence to suggest that dopamine is required for incentive learning and perhaps control of behavior by conditioned stimuli (for review, see Beninger and Miller, 1998; Sutton and Beninger, 1999). For example, systemic administration of the dopamine antagonist $\alpha$-flupenthixol attenuates operant responding for a conditioned reinforcer and the enhancement of this responding caused by amphetamine administration into the nucleus accumbens, suggesting that dopamine antagonism impairs learning of stimulus-reward relationships (Fletcher and Higgins, 1997). In agreement with our recent work showing that intra-accumbens administration of a high dose of SCH-23390 impairs both acquisition and performance of appetitive instrumental learning (Smith-Roe and Kelley, 2000), systemic SCH23390 decreases operant responding (Beninger et al., 1987) as does intra-accumbens SCH-22390 administration (Evans and Cory-Slechta, 2000). Research on the amygdala and mPFC suggests that dopamine may play a similar role in discrete components of a distributed network mediating motivated behaviors. For example, intra-amygdala SCH-23390 blocks both acquisition and expression of fear-potentiated startle (Guarraci et al., 1999; Greba and Kokkinidis, 2000). In a five-choice serial reaction time task, infusion of SCH-23390 into the mPFC impairs attentional performance in rats previously demonstrating high accuracy, whereas a D1 receptor agonist improved performance in previously low-accuracy rats (Granon et al., 2000). These results in particular suggest that, in addition to a general involvement of D1 receptors, there is also a critical level of D1 receptor activation required for optimal performance of the task (see also Williams and Goldman-Rakic, 1995). Thus, there is evidence to support the idea that activation of dopamine D1 receptors, in several discrete yet interacting brain regions, is involved in both acquisition of conditioned associations and may mediate the ability of conditioned stimuli to control behavior (Sutton and Beninger, 1999). One caveat to note in the present findings, however, is that although intra-accumbens infusion of a high dose of SCH-23390 impairs unconditioned locomotor behavior, as measured in control studies (Smith-Roe and Kelley, 2000), we did not find this to be true with SCH-23390 administration into the mPFC (see Results) (Table 1). This suggests that there are further dissociable contributions of dopamine D1 receptor activation in this network and that the consequences of D1 receptor antagonism in the accumbens may reflect the role of this region in production of motor behaviors (Kelley, 1999). Also of note is the fact that infusion of the high dose of SCH-23390 had no effect on feeding behavior (Table 1), suggesting that the motivation to obtain an unconditioned reinforcer is not affected by mPFC D1 receptor blockade.

Previous results have shown that antagonism of NMDA receptors using a high dose $(5 \mathrm{nmol})$ of AP-5 within either the nucleus accumbens core, mPFC, or amygdala completely inhibits acquisition, but not expression, of appetitive instrumental learning (Kelley et al., 1997; Baldwin et al., 2000). The present findings that co-infusion of low, and individually inactive, doses of AP-5 and SCH-23390 impairs learning, suggest that appetitive instrumental learning also requires coactivation of mPFC NMDA and D1 receptors. These results are strikingly similar to previous findings examining the effects of the same drug administration into the nucleus accumbens core (Smith-Roe and Kelley, 2000). Because mPFC co-infusion of the low doses of SCH-23390 and AP-5 had no impact on control measures of feeding and locomotor behavior (Table 1), it is unlikely that nonspecific motivational or motor effects can account for the learning deficit.

Interactions between D1 and NMDA receptors have been demonstrated in electrophysiological studies in both the mPFC and striatum, where dopaminergic terminals synapse in close apposition to glutamatergic afferents (Smith and Bolam, 1990; Carr and Sesack, 1996). For example, in both regions D1 activation potentiates NMDA receptor-mediated responses (Cepeda et al., 1993; Seamans et al., 2001; Wang and O’Donnell, 2001), and in both striatum and PFC D1 receptor activation is required for long-term potentiation (Wickens et al., 1996; Gurden et al., 2000; Kerr and Wickens, 2001). Additionally, molecular studies also provide evidence for D1-NMDA interactions. D1 receptor induction of immediate early gene expression requires NMDA receptor activation, and furthermore, either NMDA antagonism or inhibition of PKA attenuates dopamine-mediated phosphorylation of the cAMP response element-binding protein (Konradi et al., 1996; Das et al., 1997), a transcription factor thought to be an evolutionarily conserved modulator of memory processes (Silva et al., 1998). The present results found that inhibition of mPFC PKA with Rp-cAMPS also impaired acquisition of appetitive instrumental learning, and similar results have been found for the nucleus accumbens (Baldwin et al., 2002). It is likely that inhibition of PKA prevents long-term changes via inhibition of transcriptional activation. Additionally, NMDA receptor subunits present in cortical sites are phosphorylated by PKA (Leonard and Hell, 1997), suggesting that inhibition of PKA with Rp-cAMPS may impair long-term plasticity mediated by NMDA receptors in these regions. In concordance with the present data, Wang and O'Donnell (2001) found that prefrontal D1-NMDA synergy in cell excitability was blocked by PKA inhibitors. It is also of 
interest to note that optimal levels of PKA within the prefrontal cortex are required for working memory (Taylor et al., 1999).

Work in the monkey has suggested that prefrontal cortex is involved in stimulus-reinforcement associative learning (Rolls, 2000). This hypothesis is based on neurophysiological evidence demonstrating that the orbitofrontal cortex has representations of primary reinforcers, including information specifically predictive of reward value (Thorpe et al., 1983; Rolls, 1989; Critchley and Rolls, 1996; Rolls et al., 1996, 1999). Furthermore, orbitofrontal neurons are sensitive to hunger state (Critchley and Rolls, 1996) and can also detect nonreward (Thorpe et al., 1983), suggesting that this region is equipped to adapt to changes in both internal motivational states and external contingencies (Rolls, 2000). Recent lesion work involving the rat prelimbic area indeed suggests that the prefrontal cortex is involved in learning the relationship between reward outcome and behavior (Balleine and Dickinson, 1998).

As suggested by the research cited above, the contribution of the mPFC to appetitive instrumental learning likely requires a temporal and spatial convergence of motivational and sensory information, coded by glutamate, and signals of primary reinforcement, coded by dopamine. This hypothesis is supported by findings that coincident dopaminergic and glutamatergic activity leads to long-term enhancement of synaptic strength in striatal neurons (Wickens et al., 1996). Furthermore, stimulation of the ventral tegmental area has recently been shown to maintain mPFC neurons in a depolarized "up" state that may facilitate NMDA receptor-mediated plasticity (Lewis and O'Donnell, 2000). Thus, a D1-NMDA receptor interaction in the mPFC may represent a coincidence detector that serves as the molecular basis for synaptic changes involved in associative learning. Classic theories of stimulus-response (S-R) learning (Thorndike, 1911; Hull, 1943) as well as more modern interpretations of instrumental learning (Packard et al., 1989; Dickinson and Balleine, 1994) posit that multiple processes influence adaptive motor learning. These processes include acquisition of information about causal relations between response and reward (action-outcome), the current value of the reward (incentive learning), and reinforcement or strengthening of the S-R bond (habit learning) (Balleine and Dickinson, 1998). In view of the present data as well as recent work reporting a similar molecular mechanism in the nucleus accumbens (Smith-Roe and Kelley, 2000), we propose that a D1-NMDA receptor interaction and its transcriptional consequences within a distributed corticostriatal network may represent a conserved molecular mechanism underlying instrumental learning. Dynamic activity and plasticity in this network may underlie the complex processes necessary for adaptive behavioral actions.

\section{REFERENCES}

Baldwin AE, Holahan MR, Sadeghian K, Kelley AE (2000) N-methylD-aspartate receptor-dependent plasticity within a distributed corticostriatal network mediates appetitive instrumental learning. Behav Neurosci 114:84-98.

Baldwin AE, Sadeghian K, Kelley AE (2002) Appetitive instrumental learning is impaired by inhibition of cAMP-dependent protein kinase within the nucleus accumbens. Neurobiol Learn Mem, in press.

Balleine BW, Dickinson A (1998) Goal-directed instrumental action: contingency and incentive learning and their cortical substrates. Neuropharmacology 37:407-419.

Beckstead RM, Domesick VB, Nauta WJ (1979) Efferent connections of the substantia nigra and ventral tegmental area in the rat. Brain Res 175:191-217.

Beninger RJ, Miller R (1998) Dopamine D1-like receptors and rewardrelated incentive learning. Neurosci Biobehav Rev 22:335-345.

Beninger RJ, Cheng M, Hahn BL, Hoffman DC, Mazurski EJ, Morency
MA, Ramm P, Stewart RJ (1987) Effects of extinction, pimozide, SCH 23390 , and metoclopramide on food- rewarded operant responding of rats. Psychopharmacology 92:343-349.

Berridge KC, Robinson TE (1998) What is the role of dopamine in reward: hedonic impact, reward learning, or incentive salience? Brain Res Brain Res Rev 28:309-369.

Brog JS, Salyapongse A, Deutch AY, Zahm DS (1993) The patterns of afferent innervation of the core and shell in the "accumbens" part of the rat ventral striatum: immunohistochemical detection of retrogradely transported fluoro-gold. J Comp Neurol 338:255-278.

Carr DB, Sesack SR (1996) Hippocampal afferents to the rat prefrontal cortex: synaptic targets and relation to dopamine terminals. J Comp Neurol 369:1-15.

Cepeda C, Levine MS (1998) Dopamine and $N$-methyl-D-aspartate receptor interactions in the neostriatum. Dev Neurosci 20:1-18.

Cepeda C, Buchwald NA, Levine MS (1993) Neuromodulatory actions of dopamine in the neostriatum are dependent upon the excitatory amino acid receptor subtypes activated. Proc Natl Acad Sci USA 90:9576-9580.

Christie MJ, James LB, Beart PM (1985) An excitant amino acid projection from the medial prefrontal cortex to the anterior part of nucleus accumbens in the rat. J Neurochem 45:477-482.

Critchley HD, Rolls ET (1996) Hunger and satiety modify the responses of olfactory and visual neurons in the primate orbitofrontal cortex. J Neurophysiol 75:1673-1686.

Das S, Grunert M, Williams L, Vincent SR (1997) NMDA and D1 receptors regulate the phosphorylation of CREB and the induction of c-fos in striatal neurons in primary culture. Synapse 25:227-233.

Dickinson A, Balleine B (1994) Motivational control of goal-directed action. Anim Learn Behav 22:1-18.

Evans SB, Cory-Slechta DA (2000) Prefrontal cortical manipulations alter the effects of intra-ventral striatal dopamine antagonists on fixedinterval performance in the rat. Behav Brain Res 107:45-58.

Fletcher PJ, Higgins GA (1997) Differential effects of ondansetron and alpha-flupenthixol on responding for conditioned reward. Psychopharmacology (Berl) 134:64-72.

Floresco SB, Seamans JK, Phillips AG (1997) Selective roles for hippocampal, prefrontal cortical, and ventral striatal circuits in radial-arm maze tasks with or without a delay. J Neurosci 17:1880-1890.

Gaffan D, Murray EA (1990) Amygdalar interaction with the mediodorsal nucleus of the thalamus and the ventromedial prefrontal cortex in stimulus-reward associative learning in the monkey. J Neurosci 10:3479-3493.

Goldman-Rakic PS (1995a) Cellular basis of working memory. Neuron $14: 477-485$

Goldman-Rakic PS (1995b) Toward a circuit model of working memory and the guidance of voluntary motor action. In: Models of information processing in the basal ganglia (Houk JC, Davis JL, Beiser DG, ed), pp 131-148. Cambridge, MA: MIT

Granon S, Passetti F, Thomas KL, Dalley JW, Everitt BJ, Robbins TW (2000) Enhanced and impaired attentional performance after infusion of D1 dopaminergic receptor agents into rat prefrontal cortex. J Neurosci 20:1208-1215.

Greba Q, Kokkinidis L (2000) Peripheral and intraamygdalar administration of the dopamine D1 receptor antagonist SCH 23390 blocks fear-potentiated startle but not shock reactivity or the shock sensitization of acoustic startle. Behav Neurosci 114:262-272.

Guarraci FA, Frohardt RJ, Kapp BS (1999) Amygdaloid D1 dopamine receptor involvement in Pavlovian fear conditioning. Brain Res 827:28-40.

Gurden H, Takita M, Jay TM (2000) Essential role of D1 but not D2 receptors in the NMDA receptor-dependent long-term potentiation at hippocampal-prefrontal cortex synapses in vivo. J Neurosci 20:RC106(1-5).

Horvitz JC (2000) Mesolimbocortical, nigrostriatal dopamine responses to salient non- reward events Neuroscience 96:651-656.

Houk JC, Wise SP (1995) Distributed modular architectures linking basal ganglia, cerebellum, and cerebral cortex: their role in planning and controlling action. Cereb Cortex 5:95-110.

Hull CL (1943) Principles of behavior. New York: Appleton-CenturyCrofts.

Izaki Y, Hori K, Nomura M (1998) Dopamine and acetylcholine elevation on lever-press acquisition in rat prefrontal cortex. Neurosci Lett 258:33-36.

Kalivas PW (1995) Interactions between dopamine and excitatory amino acids in behavioral sensitization to psychostimulants. Drug Alcohol Depend 37:95-100.

Karler R, Calder LD, Thai LH, Bedingfield JB (1994) A dopaminergicglutamatergic basis for the action of amphetamine and cocaine. Brain Res 658:8-14.

Kelley AE (1999) Neural integrative activities of nucleus accumbens subregions in relation to learning and motivation. Psychobiology 27:198-213.

Kelley AE, Smith-Roe S, Holahan MR (1997) Response-reinforcement 
learning is dependent on NMDA receptor activation in the nucleus accumbens core. Proc Natl Acad Sci USA 94:12174-12179.

Kerr JN, Wickens JR (2001) Dopamine D-1/D-5 receptor activation is required for long-term potentiation in the rat neostriatum in vitro. J Neurophysiol 85:117-124.

Kita H, Kitai ST (1990) Amygdaloid projections to the frontal cortex and the striatum in the rat. J Comp Neurol 298:40-49.

Konradi C, Leveque JC, Hyman SE (1996) Amphetamine and dopamine-induced immediate early gene expression in striatal neurons depends on postsynaptic NMDA receptors and calcium. J Neurosci 16:4231-4239.

Leonard AS, Hell JW (1997) Cyclic AMP-dependent protein kinase and protein kinase $\mathrm{C}$ phosphorylate $N$-methyl-D-aspartate receptors at different sites. J Biol Chem 272:12107-12115.

Lewis BL, O'Donnell P (2000) Ventral tegmental area afferents to the prefrontal cortex maintain membrane potential "up" states in pyramidal neurons via D(1) dopamine receptors. Cereb Cortex 10:1168-1175.

Lindvall O, Bjorklund A, Divac I (1978) Organization of catecholamine neurons projecting to the frontal cortex in the rat. Brain Res 142:1-24.

McDonald RJ, White NM (1993) A triple dissociation of memory systems: hippocampus, amygdala, and dorsal striatum. Behav Neurosci 107:3-22.

Packard MG, Hirsh R, White NM (1989) Differential effects of fornix and caudate nucleus lesions on two radial maze tasks: evidence for multiple memory systems. J Neurosci 9:1465-1472.

Paxinos G, Watson C (1998) The rat brain in stereotaxic coordinates. San Diego: Academic.

Richardson NR, Gratton A (1996) Behavior-relevant changes in nucleus accumbens dopamine transmission elicited by food reinforcement: an electrochemical study in rat. J Neurosci 16:8160-8169.

Robinson TE, Berridge KC (1993) The neural basis of drug craving: an incentive-sensitization theory of addiction. Brain Res Brain Res Rev 18:247-291.

Robinson TE, Berridge KC (2001) Incentive-sensitization, addiction. Addiction 96:103-114.

Rolls ET (1989) Information processing in the taste system of primates. J Exp Biol 146:141-164.

Rolls ET (2000) The orbitofrontal cortex and reward. Cereb Cortex 10:284-294.

Rolls ET, Critchley HD, Mason R, Wakeman EA (1996) Orbitofrontal cortex neurons: role in olfactory and visual association learning. J Neurophysiol 75:1970-1981.

Rolls ET, Critchley HD, Browning AS, Hernadi I, Lenard L (1999) Responses to the sensory properties of fat of neurons in the primate orbitofrontal cortex. J Neurosci 19:1532-1540.

Salamone JD (1994) The involvement of nucleus accumbens dopamine in appetitive and aversive motivation. Behav Brain Res 61:117-133.

Sawaguchi T, Goldman-Rakic PS (1991) D1 dopamine receptors in prefrontal cortex: involvement in working memory. Science 251:947-950.

Schultz W, Apicella P, Ljungberg T (1993) Responses of monkey dopamine neurons to reward and conditioned stimuli during successive steps of learning a delayed response task. J Neurosci 13:900-913.

Seamans JK, Durstewitz D, Christie BR, Stevens CF, Sejnowski TJ
(2001) Dopamine D1/D5 receptor modulation of excitatory synaptic inputs to layer $\mathrm{V}$ prefrontal cortex neurons. Proc Natl Acad Sci USA 98:301-306.

Silva AJ, Kogan JK, Frankland PW, Kida S (1998) CREB and memory. Annu Rev Neurosci 21:127-148.

Smith AD, Bolam JP (1990) The neural network of the basal ganglia as revealed by the study of synaptic connections of identified neurones. Trends Neurosci 13:259-265.

Smith-Roe SL, Kelley AE (2000) Coincident activation of NMDA and dopamine D1 receptors within the nucleus accumbens core is required for appetitive instrumental learning. J Neurosci 20:7737-7742.

Smith-Roe S, Sadeghian K, Kelley AE (1999) Spatial learning and performance in the radial arm maze is impaired after $N$-methyl-D aspartate (NMDA) receptor blockade in striatal subregions. Behav Neurosci 113:703-717.

Sonsalla PK (1995) The role of $N$-methyl-D-aspartate receptors in dopaminergic neuropathology produced by the amphetamines. Drug Alcohol Depend 37:101-105.

Sutton MA, Beninger RJ (1999) Psychopharmacology of conditioned reward: evidence for a rewarding signal at D1-like dopamine receptors. Psychopharmacology (Berl) 144:95-110.

Taylor JR, Birnbaum S, Ubriani R, Arnsten AFT (1999) Activation of cAMP-dependent protein kinase A in prefrontal cortex impairs working memory performance. J Neurosci 19:RC23(1-5).

Thorndike EE (1911) Animal intelligence. New York: Macmillan.

Thorpe SJ, Rolls ET, Maddison S (1983) The orbitofrontal cortex: neuronal activity in the behaving monkey. Exp Brain Res 49:93-115.

Tremblay L, Schultz W (2000) Reward-related neuronal activity during go-nogo task performance in primate orbitofrontal cortex. J Neurophysiol 83:1864-1876.

Vanderschuren LJ, Kalivas PW (2000) Alterations in dopaminergic and glutamatergic transmission in the induction and expression of behavioral sensitization: a critical review of preclinical studies. Psychopharmacology (Berl) 151:99-120.

Verma A, Moghaddam B (1996) NMDA receptor antagonists impair prefrontal cortex function as assessed via spatial delayed alternation performance in rats: modulation by dopamine. J Neurosci 16:373-379.

Wang J, O’Donnell P (2001) D1 dopamine receptors potentiate NMDAmediated excitability increase in layer $\mathrm{V}$ prefrontal cortical pyramidal neurons Cereb Cortex 11:452-462.

Wickens JR, Begg AJ, Arbuthnott GW (1996) Dopamine reverses the depression of rat corticostriatal synapses which normally follows highfrequency stimulation of cortex in vitro. Neuroscience 70:1-5.

Williams GV, Goldman-Rakic PS (1995) Modulation of memory fields by dopamine D1 receptors in prefrontal cortex. Nature 376:572-575.

Wolf ME, Xue CJ (1998) Amphetamine and D1 dopamine receptor agonists produce biphasic effects on glutamate efflux in rat ventra tegmental area: modification by repeated amphetamine administration. J Neurochem 70:198-209.

Wolf ME, White FJ, Hu X-T (1994) MK-801 prevents alterations in the mesoaccumbens dopamine system associated with behavioral sensitization to amphetamine. J Neurosci 14:1735-1745. 